\title{
Trajectory of absolute neutrophil counts in patients treated with pegfilgrastim on the day of chemotherapy versus the day after chemotherapy
}

\author{
Yanli $\mathrm{Li}^{1} \cdot$ Zandra Klippel $^{2} \cdot$ Xiaolong Shih $^{3} \cdot$ Hong Wang $^{4} \cdot$ Maureen Reiner $^{5}$. \\ John H. Page ${ }^{6}$
}

Received: 22 December 2015 / Accepted: 13 January 2016 / Published online: 17 February 2016

(c) The Author(s) 2016. This article is published with open access at Springerlink.com

\begin{abstract}
Purpose Risk of infection increases with severity and duration of chemotherapy-induced neutropenia (CIN). Pegfilgrastim is approved for use on the day after chemotherapy to reduce incidence of infection, as manifested by febrile neutropenia (FN), in patients receiving myelosuppressive chemotherapy. In this study, we compared severity and duration of absolute neutrophil count (ANC) suppression in patients who received pegfilgrastim on the same day as chemotherapy versus the next day.

Methods We combined individual patient data from four Amgen-sponsored clinical trials in which patients with cancer were randomized to receive pegfilgrastim either the same day as chemotherapy or the next day. Severity and duration of ANC suppression were calculated using area over the curve (AOC, the area over the ANC-time response curve and below a given clinical threshold). AOC of ANC
\end{abstract}

Electronic supplementary material The online version of this article (doi:10.1007/s00280-016-2970-5) contains supplementary material, which is available to authorized users.

Yanli Li

yanli.li@amgen.com

1 Center for Observational Research, Amgen Inc., 1150 Veterans Blvd, South San Francisco, CA 94080, USA

2 Clinical Development, Amgen Inc., Thousand Oaks, CA, USA

3 SimulStat Inc., San Diego, CA, USA

4 TechData Service Company, LLC, King of Prussia, PA, USA

5 Global Biostatistical Science, Amgen Inc., Thousand Oaks, CA, USA

6 Center for Observational Research, Amgen Inc., Thousand Oaks, CA, USA and incidences of CIN and FN were compared by day of pegfilgrastim use.

Results The analysis included 95 same-day patients and 97 next-day patients. Despite similar ANC at baseline, ANC at nadir was higher among next-day patients than same-day patients. Mean AOC of ANC (cutoff $0.5 \times 10^{9} / \mathrm{L}$ ) among next-day patients was lower by 0.30 (95\% confidence interval: $0.16,0.43) 10^{9} / \mathrm{L} \times$ day than same-day patients in cycle 1 . Next-day patients had lower incidences of CIN than same-day patients, but there were no significant differences in incidences of FN.

Conclusions Patients who received pegfilgrastim the day after chemotherapy had less severe and shorter suppression of ANC than patients who received pegfilgrastim the same day as chemotherapy.

Keywords Area over the curve - Chemotherapyinduced neutropenia $\cdot$ Febrile neutropenia $\cdot$ Next-day administration $\cdot$ Pegfilgrastim $\cdot$ Same-day administration

\section{Introduction}

Neutrophils, the most abundant leukocytes in circulation, play a crucial role in innate immune responses against infections [1]. Cytotoxic chemotherapy suppresses the hematopoietic system and may lead to chemotherapyinduced neutropenia (CIN), a condition that makes patients vulnerable to potentially life-threatening infections [2]. Following initiation of myelosuppressive chemotherapy, absolute neutrophil count (ANC) follows a trajectory that includes a decline to its lowest point (the nadir) and subsequent rise as the bone marrow recovers [3]. Lower ANC (or leukocytes) at nadir and longer duration of severe CIN (or 
leukopenia) have been shown to be associated with higher risk of infection [4-6].

Neutropenia blunts the inflammatory response to nascent infections and reduces the signs and symptoms of infection; therefore, the only sign of infection in the presence of neutropenia is often fever [2]. Febrile neutropenia (FN), the combination of neutropenia and fever, is a serious toxicity of myelosuppressive chemotherapy that can lead to chemotherapy dose delays and reductions as well as increased morbidity, mortality, and healthcare resource use [7-9].

Granulocyte colony-stimulating factor (G-CSF) regulates the production of neutrophils within the bone marrow and induces proliferation and differentiation of neutrophil precursors [10, 11]. Pegfilgrastim (Neulasta ${ }^{\circledR}$, Amgen Inc., Thousand Oaks, CA, USA) is a pegylated recombinant human G-CSF that is indicated to decrease the incidence of infection, as manifested by FN, in patients with non-myeloid malignancies receiving myelosuppressive anti-cancer drugs $[12,13]$.

Neulasta ${ }^{\circledR}$ prescribing information specifies that pegfilgrastim should not be administered between 14 days before and $24 \mathrm{~h}$ after administration of chemotherapy [13]. Theoretically, the simultaneous administration of exogenous G-CSF and chemotherapy may lead to an increased pool of neutrophil precursors susceptible to destruction by chemotherapy, leading paradoxically to an increased risk of neutropenia $[14,15]$. Nevertheless, some patients still receive pegfilgrastim on the same day as chemotherapy rather than the next day [16-18].

In the current study, we pooled individual patient data from four Amgen-sponsored clinical trials in which patients were randomized to receive pegfilgrastim on the same day as chemotherapy versus the next day. The objectives of this study were to compare several metrics for severity and duration of ANC suppression and incidence proportions of $\mathrm{CIN}$ and FN among patients who received pegfilgrastim on the same day as chemotherapy versus the next day.

\section{Materials and methods}

\section{Study design and data source}

The current study is a secondary analysis of individual patient data collected in four randomized phase 2 clinical trials sponsored by Amgen Inc. The trials were conducted between 2003 and 2005 in patients with non-Hodgkin's lymphoma, breast cancer, relapsed or refractory ovarian cancer, and advanced or metastatic non-small cell lung cancer. The primary objective of the trials was to provide data on the safety and efficacy of pegfilgrastim administered on the same day as chemotherapy (within $24 \mathrm{~h}$ of chemotherapy completion) versus the next day ( $24 \mathrm{~h}$ after chemotherapy completion). The primary efficacy endpoint of all four trials was duration of grade 4 neutropenia. Criteria for the inclusion of these four trials in this analysis are shown in Supplementary material 1. Key information regarding these four trials is summarized in Supplementary material 2. In three of four trials (Amgen studies 20020134, 20020778, and 20030123), chemotherapy was administered only on day 1 of the chemotherapy cycle, and the same-day and next-day patients received pegfilgrastim on day 1 and day 2 of the cycle, respectively. In Amgen study 20030122, chemotherapy was administered over the first 5 days of the chemotherapy cycle, and the same-day and next-day patients received pegfilgrastim on day 5 and day 6 of the cycle, respectively (Supplementary material 2).

\section{Study population}

Patients were included in this analysis if they were enrolled in one of the four aforementioned randomized clinical trials and met all of the following additional inclusion criteria: baseline $\mathrm{ANC} \geq 1500 / \mu \mathrm{L}$ at initiation of chemotherapy, ANC measured at least four times per cycle in at least one cycle of the chemotherapy course under study, and normal body temperature $\left(<38{ }^{\circ} \mathrm{C}\right)$ at initiation of chemotherapy. Patients were excluded if they had an active infection that required treatment with anti-infectives within $72 \mathrm{~h}$ of chemotherapy, received prophylactic antibiotics, received pelvic irradiation or radiation therapy extending beyond a single involved field within 4 weeks of chemotherapy initiation, or had a prior malignancy in the previous 5 years.

Patients in two of the included clinical trials (Amgen studies 20020778 and 20030122) had ANC measured at least four times per cycle in both cycle 1 and cycle 3 . Patients in the other two trials (Amgen studies 20020134 and 20030123) had ANC measured at least four times per cycle only in cycle 1 . All the ANC-related analyses in the current study were conducted in cycles in which ANC was measured at least four times per cycle.

\section{Endpoints}

The primary endpoint of this study was area over the ANCtime response curve (AOC). AOC of ANC is the area above the ANC-time response curve and below the thresholds of $0.5 \times 10^{9} / \mathrm{L}$ or $1.0 \times 10^{9} / \mathrm{L}$ in a given chemotherapy cycle (shown graphically in Fig. 1). AOC of ANC measures both severity and duration of neutropenia. The more severe and the longer the duration of neutropenia, the higher the AOC. The thresholds of $0.5 \times 10^{9} / \mathrm{L}$ and $1.0 \times 10^{9} / \mathrm{L}$ are based on the Common Terminology Criteria for Adverse Events (CTCAE): an ANC $<0.5 \times 10^{9} / \mathrm{L}$ is categorized as grade 4 neutropenia, while an ANC between $0.5 \times 10^{9} / \mathrm{L}$ and $1.0 \times 10^{9} / \mathrm{L}$ is categorized as grade 3 neutropenia [19]. 
Fig. 1 ANC trajectory in patients who received pegfilgrastim on the same day as chemotherapy versus the next day. a ANC trajectory in cycle 1. Data are from eligible patients in Amgen studies 20020134, 20020778, 20030122, and 20030123. b ANC trajectory in cycle 3. Data are from eligible patients in Amgen studies 20020778 and 20030122. Red squares represent daily median ANC values for patients who received pegfilgrastim on the same day as chemotherapy. Green squares represent daily median ANC values for patients who received pegfilgrastim on the day after chemotherapy. Error bars represent Q1 and Q3 of daily ANC values. $A O C$ is the area above the ANC-time response curve and below a given clinical threshold $\left(\mathrm{ANC}<1.0 \times 10^{9} / \mathrm{L}\right.$ or $\left.\mathrm{ANC}<0.5 \times 10^{9} / \mathrm{L}\right)$. The cross-hatched area represents $\mathrm{AOC}$ for $\mathrm{ANC}<1.0 \times 10^{9} / \mathrm{L}$. ANC values are shown on a natural logarithmic scale. Days are numbered from chemotherapy initiation: day 1 is the day of chemotherapy; day 2 is the day after chemotherapy. $A N C$ absolute neutrophil count; $A O C$ area over the curve; $Q 1$ quartile 1; Q3 quartile 3
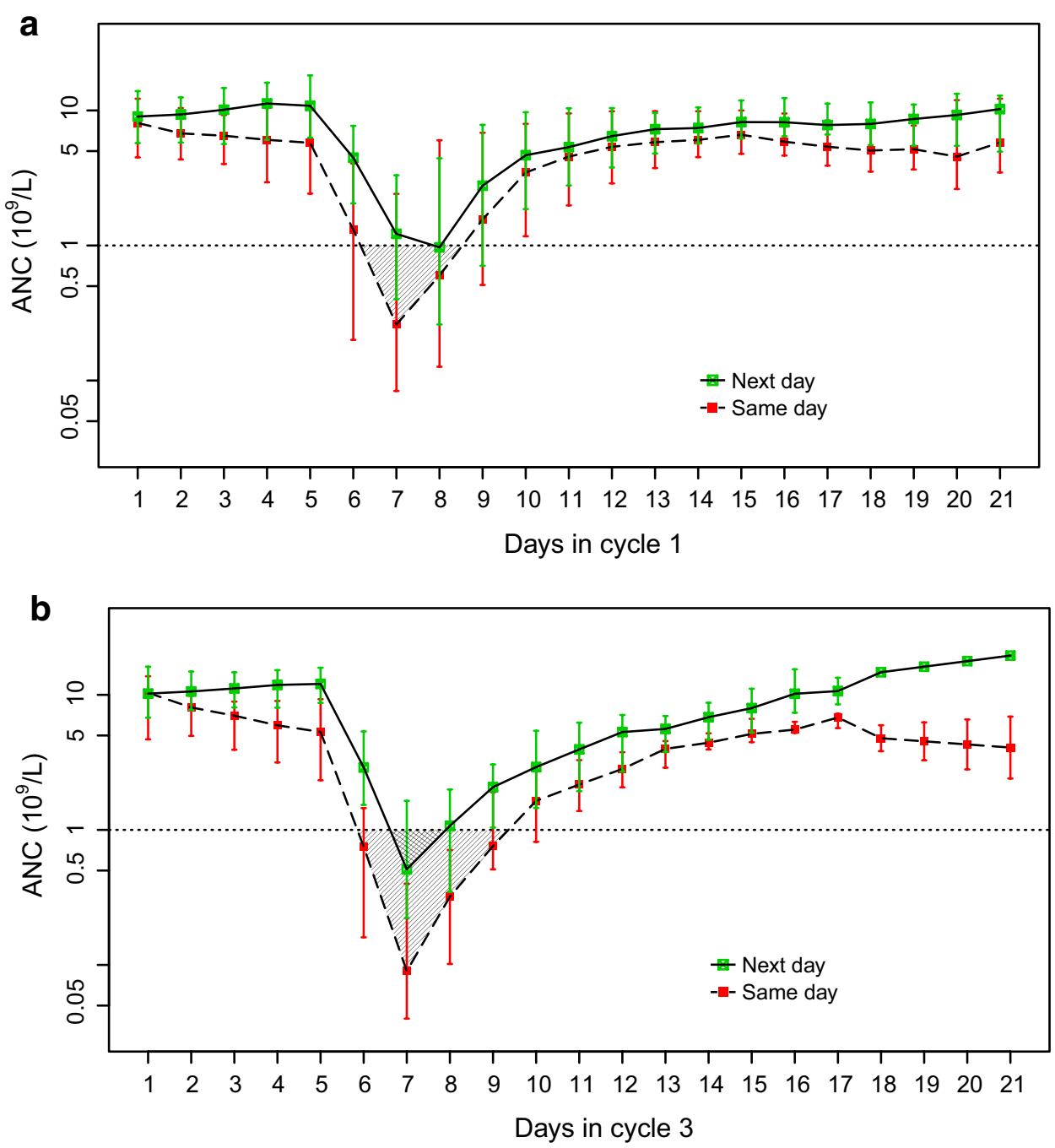

The secondary endpoints of this study were ANC at nadir, time to ANC nadir, and incidence proportions of grade $4 \mathrm{CIN}\left(\mathrm{ANC}<0.5 \times 10^{9} / \mathrm{L}\right)$, grade $3 / 4 \mathrm{CIN}$ $\left(\right.$ ANC $\left.<1.0 \times 10^{9} / \mathrm{L}\right)$, grade $4 \mathrm{FN}$, and grade $3 / 4 \mathrm{FN}$ within a chemotherapy cycle. Grade 4 and grade $3 / 4$ FN were defined as an infectious episode (body temperature $\geq 38.2{ }^{\circ} \mathrm{C}$, infection-related hospitalization, or infectionrelated adverse event) occurring on the same day or within 1 day of grade 4 or grade 3/4 neutropenia, respectively.

\section{Statistical analysis}

Descriptive analyses were conducted to characterize demographics, disease characteristics, and chemotherapy treatments in the overall study population and in each of the treatment groups (same-day versus next-day pegfilgrastim use). The two-sample $t$ test was used to assess differences in continuous variables, and the Chi-square test was used to assess differences in categorical variables between the treatment groups. No multiplicity adjustment was used, and $p$ values should be considered nominal. Body surface area was calculated using the Mosteller formula [20]. Risk of FN for each chemotherapy regimen was based on the National Comprehensive Cancer Network (NCCN) guidelines [21]. For regimens that remain unclassified, FN incidence in the placebo arms (no G-CSF) of Amgen-sponsored clinical trials and FN risk reported in the literature were used to determine FN risk category [22].

Baseline ANC values, ANC at nadir, and time to ANC nadir were described by treatment group for each cycle with $\geq 4$ ANC measurements (cycles 1 and 3). The loglinear interpolation technique [23] was used to derive ANC on days without a measurement using the adjacent ANC measurements from each patient. ANC nadir was the lowest ANC value that occurred during the chemotherapy cycle. Time to ANC nadir was calculated as the number of days from chemotherapy initiation to ANC nadir. Distributions of all ANC metrics were skewed; thus, the Wilcoxon rank sum test was used to compare the differences between the two treatment groups. Differences in the distribution 
Table 1 Patient disposition after applying each of the inclusion/exclusion criteria

\begin{tabular}{|c|c|c|c|c|c|c|c|c|c|c|}
\hline \multirow[t]{2}{*}{ Inclusion/exclusion criteria } & \multicolumn{2}{|c|}{$\begin{array}{l}\text { Study } 20020134 \\
\text { NHL }\end{array}$} & \multicolumn{2}{|c|}{$\begin{array}{l}\text { Study } 20020778 \\
\text { Breast Cancer }\end{array}$} & \multicolumn{2}{|c|}{$\begin{array}{l}\text { Study } 20030122 \\
\text { Ovarian Cancer }\end{array}$} & \multicolumn{2}{|c|}{$\begin{array}{l}\text { Study } 20030123 \\
\text { NSCLC }\end{array}$} & \multicolumn{2}{|l|}{ All studies } \\
\hline & Same day & Next day & Same day & Next day & Same day & Next day & Same day & Next day & Same day & Next day \\
\hline $\begin{array}{l}\text { Patients enrolled and received } \\
\text { assigned drugs }\end{array}$ & 36 & 39 & 45 & 43 & 8 & 11 & 43 & 44 & 132 & 137 \\
\hline Baseline ANC $\geq 1500 / \mu \mathrm{L}$ & 36 & 37 & 45 & 43 & 8 & 11 & 43 & 44 & 132 & 135 \\
\hline $\begin{array}{l}\text { Normal baseline body } \\
\text { temperature }\end{array}$ & 35 & 37 & 45 & 43 & 8 & 11 & 43 & 44 & 131 & 135 \\
\hline $\begin{array}{l}\text { No history of cancer within } \\
\text { the last } 5 \text { years }\end{array}$ & 30 & 30 & 32 & 32 & 6 & 7 & 38 & 34 & 106 & 103 \\
\hline No history of chemotherapy & 30 & 30 & 32 & 32 & 5 & 7 & 38 & 34 & 105 & 103 \\
\hline No recent radiation therapy & 30 & 30 & 32 & 31 & 5 & 7 & 34 & 33 & 101 & 101 \\
\hline $\begin{array}{l}\text { ANC measured } \geq 4 \text { times in } \\
\text { cycle } 1\end{array}$ & 29 & 29 & 32 & 30 & 5 & 6 & 29 & 32 & 95 & 97 \\
\hline
\end{tabular}

All numbers indicate number of patients

$A N C$ absolute neutrophil count, $N H L$ non-Hodgkin's lymphoma; NSCLC non-small cell lung cancer

of time to ANC nadir ( $<7,7,8$, and $>8$ days) between the two groups were tested using the Chi-square test or Fisher's exact test (if expected cell frequency was $<5$ ). A sensitivity analysis was performed to compare time to ANC nadir for the studies in which chemotherapy was administered only on day 1 of the chemotherapy cycle (Amgen studies 20020134, 20020778, and 20030123), and a separate sensitivity analysis was performed to compare time to ANC nadir for the study in which chemotherapy was administered over the first 5 days of the chemotherapy cycle (Amgen study 20030122).

AOC of the ANC-time response curve (below the thresholds of $0.5 \times 10^{9} / \mathrm{L}$ or $1.0 \times 10^{9} / \mathrm{L}$ ) was calculated using the Riemann sum method, assuming ANC values to be constant within each day [24]. Due to the large proportion of patients with an AOC of 0 (e.g., $35.8 \%$ of sameday patients and $51.0 \%$ of next-day patients had an AOC of 0 below the threshold of $0.5 \times 10^{9} / \mathrm{L}$ in cycle 1 ), median AOC might not be meaningful. Mean AOC of ANC was therefore calculated for each group as were differences in mean AOC of ANC between patients who received pegfilgrastim on the same day as chemotherapy versus the next day. Differences in mean AOC were calculated in cycle 1 or cycle 3 separately using linear regression and in the two cycles combined using linear mixed-effect regression to control for within-patient and within-study correlations. Age (as a linear continuous variable) and Eastern Cooperative Oncology Group (ECOG) performance status (0, 1 , and $2-3$ as a categorical variable), the covariates with imbalanced distributions between the two groups, were controlled for in the adjusted model. A bootstrap procedure was used to estimate the $95 \%$ confidence intervals (CIs) for mean AOC difference. One thousand bootstrap samples were first selected from AOC estimates using stratified random sampling (by day of pegfilgrastim use and study) with replacement. Mean AOC differences by day of pegfilgrastim use within each of the 1000 replicates were then estimated. The 2.5th and 97.5th percentiles of the bootstrap samples were used as the $95 \%$ CIs of the mean AOC difference.

Incidence proportions of CIN and FN within a chemotherapy cycle were calculated by day of pegfilgrastim use for cycles 1 and 3. A generalized linear mixed model with logit link function was used to compare the odds of CIN and FN in next-day versus same-day patients, adjusting for age (as a linear continuous variable) and ECOG performance status $(0,1$, and $2-3$ as a categorical variable) in cycle 1 , cycle 3 , and cycles 1 and 3 combined. Within-study correlation and within-patient correlation in the combined analysis of cycles 1 and 3 were controlled for by including random intercepts in the mixed model.

\section{Results}

\section{Clinical trials and patients}

Four randomized phase 2 clinical trials were identified in which patients were allocated to receive pegfilgrastim on the same day as chemotherapy versus the next day. A total of 192 patients in these trials were eligible for inclusion in the current study: 95 patients who received pegfilgrastim on the same day as chemotherapy and 97 who received pegfilgrastim on the next day. Patient disposition by inclusion and exclusion criteria for each of the studies and for all studies combined is shown in Table 1. 
Table 2 Baseline demographics, disease characteristics, and treatment parameters of the study population

\begin{tabular}{|c|c|c|c|c|}
\hline & Overall $(N=192)$ & Same day $(N=95)$ & Next day $(N=97)$ & $p$ value $^{\mathrm{a}}$ \\
\hline \multicolumn{5}{|l|}{ Sex, $n(\%)$} \\
\hline Male & $62(32.3)$ & $31(32.6)$ & $31(32.0)$ & \multirow[t]{2}{*}{0.921} \\
\hline Female & $130(67.7)$ & $64(67.4)$ & $66(68.0)$ & \\
\hline \multicolumn{5}{|l|}{ Race, $n(\%)$} \\
\hline White or Caucasian & $155(80.7)$ & $77(81.1)$ & $78(80.4)$ & \multirow[t]{3}{*}{0.180} \\
\hline Black or African American & $21(10.9)$ & $13(13.7)$ & $8(8.2)$ & \\
\hline Other & $16(8.3)$ & $5(5.3)$ & $11(11.3)$ & \\
\hline \multicolumn{5}{|l|}{ Age, years } \\
\hline Mean \pm SD & $58.9 \pm 12.7$ & $57.5 \pm 12.7$ & $60.4 \pm 12.7$ & 0.114 \\
\hline \multicolumn{5}{|c|}{ ECOG performance status, $n(\%)$} \\
\hline 0 & $105(54.7)$ & $58(61.1)$ & $47(48.5)$ & \multirow[t]{3}{*}{0.191} \\
\hline 1 & $82(42.7)$ & $35(36.8)$ & $47(48.5)$ & \\
\hline 2 & $5(2.6)$ & $2(2.1)$ & $3(3.1)$ & \\
\hline \multicolumn{5}{|l|}{ BSA, $\mathrm{m}^{2}$} \\
\hline Mean \pm SD & $1.86 \pm 0.24$ & $1.87 \pm 0.24$ & $1.86 \pm 0.25$ & 0.739 \\
\hline \multicolumn{5}{|l|}{ BMI, $\mathrm{kg} / \mathrm{m}^{2}$} \\
\hline Mean \pm SD & $27.34 \pm 5.76$ & $27.07 \pm 5.57$ & $27.61 \pm 5.95$ & 0.522 \\
\hline \multicolumn{5}{|l|}{ Primary tumor type, $n(\%)$} \\
\hline Breast cancer & $62(32.3)$ & $32(33.7)$ & $30(30.9)$ & \multirow[t]{4}{*}{0.963} \\
\hline Non-small cell lung cancer & $61(31.8)$ & $29(30.5)$ & $32(33.0)$ & \\
\hline Non-Hodgkin's lymphoma & $58(30.2)$ & $29(30.5)$ & 29 (29.9) & \\
\hline Ovarian cancer & $11(5.7)$ & $5(5.3)$ & $6(6.2)$ & \\
\hline \multicolumn{5}{|l|}{ Tumor stage $^{\mathrm{b}}, n(\%)$} \\
\hline Non-advanced & $99(51.6)$ & $51(53.7)$ & $48(49.5)$ & \multirow[t]{2}{*}{0.560} \\
\hline Advanced & $93(48.4)$ & $44(46.3)$ & $49(50.5)$ & \\
\hline \multicolumn{5}{|l|}{ Chemotherapy regimen, $n(\%)$} \\
\hline Intermediate risk of $\mathrm{FN}^{\mathrm{c}}$ & $119(62.0)$ & $58(61.1)$ & $61(62.9)$ & \multirow[t]{2}{*}{0.794} \\
\hline High risk of $\mathrm{FN}^{\mathrm{d}}$ & $73(38.0)$ & $37(38.9)$ & $36(37.1)$ & \\
\hline
\end{tabular}

$B M I$ body mass index, $B S A$ body surface area, $E C O G$ eastern cooperative oncology group, $F N$ febrile neutropenia, $S D$ standard deviation

a Two-sample $t$ test was used to test differences for continuous variables, and Chi-square test or Fisher's exact test (if expected cell frequency was $<5$ ) were used to test differences for categorical variables between same-day and next-day patients. No multiplicity adjustment was used and $p$ values should be considered nominal

b Stages I, II, and III or "limited" were classified as non-advanced; stage IV or "extensive" were classified as advanced

c Regimens with an intermediate risk (10-20\%) of FN included: 21-day R-CHOP (cyclophosphamide, doxorubicin, vincristine, prednisone, and rituximab) and 21-day carboplatin and docetaxel

${ }^{\mathrm{d}}$ Regimens with a high risk (>20\%) of FN included: 21-day TAC (docetaxel, doxorubicin, and cyclophosphamide) and 21-day topotecan
Of the eligible patients, most were female $(67.7 \%)$, white $(80.7 \%)$, and had an ECOG performance status of $0(54.7 \%)$. Mean ( \pm standard deviation $[\mathrm{SD}])$ age of the patients was $58.9( \pm 12.7)$ years. Primary tumor types were breast cancer $(32.3 \%)$, non-small cell lung cancer $(31.8 \%)$, non-Hodgkin's lymphoma (30.2\%), and ovarian cancer $(5.7 \%)$. About half of the patients $(48.4 \%)$ had advanced tumors (stage IV or "extensive"). Most patients $(62.0 \%)$ received chemotherapy regimens with an intermediate risk (10-20\%) of FN. Demographics, disease characteristics, and chemotherapy regimen FN risk are shown in Table 2. Overall, demographics and disease characteristics were balanced between the same-day and nextday groups.

\section{ANC trajectory}

ANC trajectories of the patients who received pegfilgrastim on the same day as chemotherapy and those who received pegfilgrastim the next day are shown in Fig. 1. In 
Table 3 ANC trajectory in patients who received pegfilgrastim on the same day as chemotherapy versus the next day in cycle 1 and cycle 3

\begin{tabular}{|c|c|c|c|}
\hline $\begin{array}{l}\text { ANC trajectory } \\
\text { metrics }\end{array}$ & Same day & Next day & $p$ value $^{\mathrm{a}}$ \\
\hline \multicolumn{4}{|l|}{ Cycle 1} \\
\hline \multicolumn{4}{|c|}{ Baseline ANC $\left(10^{9} / \mathrm{L}\right)$} \\
\hline Mean $\pm \mathrm{SD}\left(n^{\mathrm{b}}\right)$ & $8.99 \pm 5.78(94)$ & $9.64 \pm 5.98(96)$ & \\
\hline Median (Q1, Q3) & $7.14(4.42,12.18)$ & $8.08(5.31,13.39)$ & 0.404 \\
\hline \multicolumn{4}{|c|}{ ANC at nadir $\left(10^{9} / \mathrm{L}\right)$} \\
\hline Mean $\pm \mathrm{SD}\left(n^{\mathrm{b}}\right)$ & $1.33 \pm 2.32(95)$ & $1.83 \pm 2.96(96)$ & \\
\hline Median (Q1, Q3) & $0.13(0.04,1.31)$ & $0.54(0.11,2.04)$ & 0.003 \\
\hline \multicolumn{4}{|c|}{ Time to ANC nadir (days) } \\
\hline Mean $\pm \operatorname{SD}\left(n^{\mathrm{b}}\right)$ & $7.52 \pm 2.48(95)$ & $7.61 \pm 1.43(96)$ & \\
\hline Median (Q1, Q3) & $7.00(7.00,8.00)$ & $7.00(7.00,8.00)$ & 0.019 \\
\hline \multicolumn{4}{|c|}{ Time to ANC nadir distribution, $n(\%)$} \\
\hline$<7$ days & $21(22.1)$ & $7(7.3)$ & 0.028 \\
\hline 7 days & $40(42.1)$ & $43(44.8)$ & \\
\hline 8 days & $23(24.2)$ & $30(31.3)$ & \\
\hline$>8$ days & $11(11.6)$ & $16(16.7)$ & \\
\hline \multicolumn{4}{|l|}{ Cycle 3} \\
\hline \multicolumn{4}{|c|}{ Baseline ANC $\left(10^{9} / \mathrm{L}\right)$} \\
\hline Mean $\pm \operatorname{SD}\left(n^{\mathrm{b}}\right)$ & $8.65 \pm 4.74(30)$ & $9.32 \pm 5.33(33)$ & \\
\hline Median (Q1, Q3) & $8.67(4.92,12.14)$ & $7.99(4.34,13.90)$ & 0.549 \\
\hline \multicolumn{4}{|c|}{ ANC at nadir $\left(10^{9} / \mathrm{L}\right)$} \\
\hline Mean $\pm \mathrm{SD}\left(n^{\mathrm{b}}\right)$ & $0.27 \pm 0.50(30)$ & $0.74 \pm 0.93(33)$ & \\
\hline Median (Q1, Q3) & $0.07(0.04,0.27)$ & $0.37(0.14,1.00)$ & $<0.001$ \\
\hline \multicolumn{4}{|c|}{ Time to ANC nadir (days) } \\
\hline Mean $\pm \operatorname{SD}\left(n^{\mathrm{b}}\right)$ & $7.53 \pm 0.73(30)$ & $7.70 \pm 0.88(33)$ & \\
\hline Median (Q1, Q3) & $7.00(7.00,8.00)$ & $7.00(7.00,8.00)$ & 0.503 \\
\hline \multicolumn{4}{|c|}{ Time to ANC nadir distribution ${ }^{\mathrm{c}} n(\%)$} \\
\hline$\leq 7$ days & $18(60.0)$ & $17(51.5)$ & 0.829 \\
\hline 8 days & $8(26.7)$ & $11(33.3)$ & \\
\hline$>8$ days & $4(13.3)$ & $5(15.2)$ & \\
\hline
\end{tabular}

Analyses in cycle 1 include data from eligible patients in Amgen studies 20020134, 20020778, 20030122, and 20030123 and in cycle 3 include data from eligible patients in Amgen studies 20020778 and 20030122

Bold indicates $p<0.05$

$A N C$ absolute neutrophil count; $Q 1$ quartile 1; $Q 3$ quartile $3 ; S D$ standard deviation

${ }^{a}$ Wilcoxon rank sum test was used to test differences of baseline ANC, ANC at nadir, and time to nadir (continuous), and Chi-square test or Fisher's exact test (if expected cell frequency was $<5$ ) was used to test difference of time to nadir distribution $(<7$ days, 7 days, 8 days, and $>8$ days) between same-day versus next-day patients

b The $n$ for each parameter (of each treatment arm) is the number of patients eligible for the corresponding statistics in cycle 1 or cycle 3

c No patients reached ANC nadir in $<7$ days in cycle 3, so $<7$ days and 7 days were combined

both cycle 1 (Fig. 1a) and cycle 3 (Fig. 1b), the ANC trajectories of same-day patients and next-day patients began to diverge on the day after chemotherapy (day 2). ANC at nadir was lower among same-day patients than among next-day patients in both cycle 1 and cycle 3 . ANC values returned to baseline sooner and remained higher throughout the cycle among next-day patients than among sameday patients in both cycles.

Key statistics of the ANC trajectory of patients in this study are shown in Table 3. Baseline ANC values were not different between same-day and next-day patients $(p>0.05)$. In contrast, ANC at nadir was significantly lower among same-day patients than among next-day patients in both cycle 1 (median [Q1, Q3]: 0.13 [0.04, 1.31] versus 0.54 $[0.11,2.04] \times 10^{9} / \mathrm{L}, p=0.003$ ) and cycle 3 (median [Q1, Q3]: $0.07[0.04,0.27]$ versus $0.37[0.14,1.00] \times 10^{9} / \mathrm{L}$, $p<0.001)$. Although the mean or median time to ANC nadir was similar between the two treatment groups in cycle 1, same-day patients tended to reach ANC nadir earlier than next-day patients: 22.1 versus $7.3 \%$ reached ANC nadir within 7 days after chemotherapy in cycle 1 (Table 3). No significant differences in time to ANC nadir were observed in cycle 3 (Table 3 ). In the sensitivity analysis, we observed that same-day patients tended to reach ANC nadir earlier than next-day patients in cycle 1 for studies in which chemotherapy was administered only on day 1 of the chemotherapy cycle (Supplementary material 3 ). Only one study with a very small sample size $(n=11$ in cycle $1, n=7$ in cycle 3 ) had chemotherapy administered over multiple days of the chemotherapy cycle. In this study, no difference in time to ANC nadir was observed between same-day and next-day patients (Supplementary material 4).

\section{Area over the ANC-time response curve}

AOC of ANC, a composite measure of duration and severity of ANC suppression, was significantly higher among same-day patients than among next-day patients (Table 4). In cycle 1 , when ANC $<0.5 \times 10^{9} / \mathrm{L}$ was used as the threshold, mean AOC of ANC was higher by 0.30 (95\% CI $0.16,0.43) 10^{9} / \mathrm{L} \times$ day among same-day patients than among next-day patients. When ANC $<1.0 \times 10^{9} / \mathrm{L}$ was used as the threshold, mean AOC of ANC was higher by 0.73 (95\% CI $0.37,1.05) 10^{9} / \mathrm{L} \times$ day among same-day patients. In cycle 3 , when both ANC $<0.5 \times 10^{9} / \mathrm{L}$ and ANC $<1.0 \times 10^{9} / \mathrm{L}$ were used as the thresholds, AOC was significantly higher among same-day patients than among next-day patients. Similar findings were observed in the analysis of cycles 1 and 3 combined (Table 4).

\section{Chemotherapy-induced neutropenia and febrile neutropenia}

Incidence proportions of $\mathrm{CIN}$ and $\mathrm{FN}$ within the chemotherapy cycle among same-day and next-day patients are shown in Table 5. Incidence proportion of grade 4 CIN was significantly 
Table 4 Comparison of mean AOC of ANC in patients who received pegfilgrastim on the same day as chemotherapy versus the next day in cycle 1 and cycle 3

\begin{tabular}{|c|c|c|c|c|c|}
\hline AOC threshold & Cycle & Day of pegfilgrastim use & $\begin{array}{l}\text { Mean } \pm \operatorname{SD} \text { AOC }\left(n^{\mathrm{a}}\right) \\
10^{9} / \mathrm{L} \times \text { day }\end{array}$ & $\begin{array}{l}\text { Crude Mean AOC } \\
\text { Difference }(95 \% \mathrm{CI}) \\
10^{9} / \mathrm{L} \times \text { day }\end{array}$ & $\begin{array}{l}\text { Adjusted Mean } \mathrm{AOC}^{\mathrm{b}} \\
\text { Difference }(95 \% \mathrm{CI}) \\
10^{9} / \mathrm{L} \times \text { day }\end{array}$ \\
\hline \multirow[t]{5}{*}{$<0.5 \times 10^{9} / \mathrm{L}$} & Cycle 1 & Same day & $0.65 \pm 0.65(95)$ & $0.31(0.17,0.43)$ & $0.30(0.16,0.43)$ \\
\hline & & Next day & $0.34 \pm 0.49(96)$ & & \\
\hline & Cycle 3 & Same day & $0.74 \pm 0.50(30)$ & $0.47(0.28,0.64)$ & $0.43(0.23,0.61)$ \\
\hline & & Next day & $0.27 \pm 0.33(33)$ & & \\
\hline & Cycles 1 and $3^{\mathrm{c}}$ & & & $0.33(0.20,0.45)$ & $0.36(0.22,0.49)$ \\
\hline \multirow[t]{5}{*}{$<1.0 \times 10^{9} / \mathrm{L}$} & Cycle 1 & Same day & $1.85 \pm 1.71(95)$ & $0.75(0.41,1.04)$ & $0.73(0.37,1.05)$ \\
\hline & & Next day & $1.10 \pm 1.31(96)$ & & \\
\hline & Cycle 3 & Same day & $2.23 \pm 1.18(30)$ & $1.21(0.74,1.65)$ & $1.11(0.63,1.55)$ \\
\hline & & Next day & $1.02 \pm 0.96(33)$ & & \\
\hline & Cycles 1 and $3^{\mathrm{c}}$ & & & $0.82(0.50,1.12)$ & $0.88(0.54,1.20)$ \\
\hline
\end{tabular}

Mean AOC difference $=$ mean AOC in same-day patients-mean AOC in next-day patients; analyses in cycle 1 include data from eligible patients in Amgen studies 20020134, 20020778, 2003012, and 20030123 and in cycle 3 include data from eligible patients in Amgen studies 20020778 and 20030122

Bold indicates that $95 \%$ CIs for crude oradjusted mean AOC difference do not include 0

$A O C$ area over the curve; $A N C$ absolute neutrophil count; $C I$ confidence interval; ECOG Eastern Cooperative Oncology Group; SD standard deviation

${ }^{\text {a }}$ The $n$ for each parameter (of each treatment arm) is the number of patients eligible for the corresponding statistics in cycle 1 or cycle 3

b Covariates included in the adjusted model were age and ECOG performance status

${ }^{c}$ Linear mixed-effect regression model was used to calculate mean AOC difference in cycles 1 and 3 combined. Within-study and within-patient correlations were controlled for in the analysis. Bootstrap procedure was used to derive $95 \%$ CIs

lower among next-day patients than among same-day patients in both cycle 1 (49.0 versus $64.2 \%$, adjusted odds ratio [OR] [95\% CI] $0.23[0.09,0.62])$ and cycle 3 (57.6 versus $83.3 \%$, adjusted OR [95\% CI] 0.19 [0.04, 0.79]). In cycles 1 and 3 combined, next-day patients had significantly lower odds of having grade $4 \mathrm{CIN}$ (adjusted OR [95\% CI] 0.23 [0.10, 0.49]).

Incidence proportion of grade $3 / 4 \mathrm{CIN}$ was not significantly different between same-day versus next-day patients in cycles 1 and 3 separately: cycle 1 (65.6 versus $72.6 \%$, adjusted OR [95\% CI] $0.48[0.17,1.35])$ and cycle $3(72.7$ versus $93.3 \%$, adjusted OR [95\% CI] 0.13 [0.02, 1.02]). However, in cycles 1 and 3 combined, the incidence proportion of grade 3/4 CIN was statistically lower among next-day patients than among same-day patients (adjusted OR [95\% CI] $0.36[0.15,0.87])$.

No statistically significant differences were observed between same-day and next-day patients in the incidence proportions of grade $4 \mathrm{FN}$ or grade $3 / 4 \mathrm{FN}$ in cycle 1 , cycle 3 , or cycles 1 and 3 combined (Table 5).

\section{Discussion}

Several randomized, placebo-controlled clinical trials have shown that patients with cancer who were treated with chemotherapy and prophylactic G-CSF experienced substantially less severe suppression of ANC, more rapid recovery of ANC, and lower incidence of infection (characterized by FN) than patients who did not receive prophylactic G-CSF [12, 25, 26]. In the current study, patients who received pegfilgrastim prophylaxis on the day after chemotherapy ( $24 \mathrm{~h}$ after chemotherapy completion) had a less severe fall in ANC and more rapid recovery of ANC than patients who received pegfilgrastim on the same day as chemotherapy (within $24 \mathrm{~h}$ of chemotherapy completion).

Previous studies have provided some evidence that patients with cancer who had lower ANCs and longer duration of severe CIN following chemotherapy were at higher risk of developing infection [4, 27]. Each unit increase in AOC of ANC $\left(10^{9} / \mathrm{L} \times\right.$ day $)$ below the threshold of ANC $<0.5 \times 10^{9} / \mathrm{L}$ was found to be associated with a significantly increased risk of infection-related hospitalization (hazard ratio [95\% CI] 1.98 [1.35, 2.90]) [28]. In this study, we did not find a statistically significant difference in the incidences of FN between patients who received pegfilgrastim prophylaxis on the same day as chemotherapy versus the next day. This is likely due to the limited statistical power of the study. The study included 192 patients and had about $30 \%$ power to detect a relative risk of 0.6.

Burris et al. [29] analyzed ANC data from the same four clinical trials included in this analysis; however, the objectives and analytical approaches of that study were different 
Table 5 Comparison of incidence proportions of CIN and FN in patients who received pegfilgrastim on the same day as chemotherapy versus the next day in cycles 1 and 3

\begin{tabular}{|c|c|c|c|c|c|}
\hline Neutropenic event & Cycle & Day of pegfilgrastim use & $\begin{array}{l}\text { Cases/patients (incidence } \\
\text { proportion) }\end{array}$ & Crude OR (95\% CI) & Adjusted OR $(95 \% \mathrm{CI})^{\mathrm{a}}$ \\
\hline \multirow[t]{5}{*}{ Grade 3/4 CIN } & \multirow[t]{2}{*}{ Cycle 1} & Same day & $69 / 95(72.6 \%)$ & Reference & Reference \\
\hline & & Next day & $63 / 96(65.6 \%)$ & $0.58(0.22,1.55)$ & $0.48(0.17,1.35)$ \\
\hline & \multirow[t]{2}{*}{ Cycle 3} & Same day & $28 / 30(93.3 \%)$ & Reference & Reference \\
\hline & & Next day & $24 / 33(72.7 \%)$ & $0.12(0.01,0.95)$ & $0.13(0.02,1.02)$ \\
\hline & \multicolumn{3}{|l|}{ Cycles 1 and $3^{b}$} & $0.41(0.17,0.94)$ & $0.36(0.15,0.87)$ \\
\hline \multirow[t]{5}{*}{ Grade 4 CIN } & \multirow[t]{2}{*}{ Cycle 1} & Same day & $61 / 95(64.2 \%)$ & Reference & Reference \\
\hline & & Next day & $47 / 96(49.0 \%)$ & $0.31(0.12,0.77)$ & $0.23(0.09,0.62)$ \\
\hline & \multirow[t]{2}{*}{ Cycle 3} & Same day & $25 / 30(83.3 \%)$ & Reference & Reference \\
\hline & & Next day & $19 / 33(57.6 \%)$ & $0.22(0.06,0.87)$ & $0.19(0.04,0.79)$ \\
\hline & \multicolumn{3}{|l|}{ Cycles 1 and $3^{b}$} & $0.29(0.14,0.60)$ & $0.23(0.10,0.49)$ \\
\hline \multirow[t]{5}{*}{ Grade $3 / 4$ FN } & \multirow[t]{2}{*}{ Cycle 1} & Same day & $16 / 95(16.8 \%)$ & Reference & Reference \\
\hline & & Next day & $10 / 96(10.4 \%)$ & $0.58(0.24,1.40)$ & $0.59(0.24,1.45)$ \\
\hline & \multirow[t]{2}{*}{ Cycle 3} & Same day & $2 / 30(6.7 \%)$ & Reference & Reference \\
\hline & & Next day & $2 / 33(6.1 \%)$ & $0.90(0.11,7.14)$ & $1.02(0.12,8.42)$ \\
\hline & \multicolumn{3}{|l|}{ Cycles 1 and $3^{\mathrm{b}}$} & $0.62(0.28,1.39)$ & $0.66(0.29,1.49)$ \\
\hline \multirow[t]{5}{*}{ Grade 4 FN } & \multirow[t]{2}{*}{ Cycle 1} & Same day & $16 / 95(16.8 \%)$ & Reference & Reference \\
\hline & & Next day & $9 / 96(9.4 \%)$ & $0.51(0.21,1.27)$ & $0.53(0.21,1.32)$ \\
\hline & \multirow[t]{2}{*}{ Cycle 3} & Same day & $2 / 30(6.7 \%)$ & Reference & Reference \\
\hline & & Next day & $2 / 33(6.1 \%)$ & $0.90(0.11,7.14)$ & $1.02(0.12,8.42)$ \\
\hline & Cycles 1 and $3^{b}$ & & & $0.56(0.25,1.28)$ & $0.60(0.26,1.38)$ \\
\hline
\end{tabular}

Analyses in cycle 1 include data from eligible patients in Amgen studies 20020134, 20020778, 20030122, and 20030123 and in cycle 3 include data from eligible patients in Amgen studies 20020778 and 20030122

Bold indicates that $95 \%$ CIs for crude ORor adjusted OR do not include 1

CI confidence interval; $C I N$ chemotherapy-induced neutropenia; ECOG Eastern Cooperative Oncology Group; $F N$ febrile neutropenia; $O R$ odds ratio

${ }^{\text {a }}$ Covariates adjusted in the generalized linear mixed model included age and ECOG performance status

b Generalized linear mixed model using logit link function (with random intercepts to control for the within-study and within-patient correlations) was used to calculate the ORs (95\% CIs) for cycles 1 and 3 combined

from the current study. Burris et al. presented ANC data, such as ANC nadir and incidence and duration of grade 4 neutropenia in cycle 1 , for each individual trial. We pooled individual patient data from the four trials and performed a statistical analysis of the shape of the ANC trajectories by using AOC of ANC. Two additional clinical trials evaluated the difference between same-day and next-day pegfilgrastim prophylaxis. Saven et al. [30] reported higher incidence of grade $4 \mathrm{CIN}$ among same-day patients but similar incidence of FN, while Belani et al. [31] reported no difference in the incidences of CIN or FN by day of pegfilgrastim use. Results from observational studies are also inconsistent, which might be explained by heterogeneous study designs, possible selection bias, and confounding [18, 32-35]. Also, most of the observational studies had relatively small sample sizes [32-35]. One recent observational study retrospectively analyzed 45,592 patients (4336 same day, 32,759 next day) from two private US healthcare claims databases. The study reported that odds of FN were significantly higher among patients who received pegfilgrastim on the same day as chemotherapy versus the next day (OR [95\% CI] $1.6[1.3$, 1.9] for cycle 1; OR [95\% CI] 1.5 [1.3, 1.6] for all cycles combined) [18]. The direction and magnitude of the associations reported in that study are similar to those reported here.

The 2015 update to the American Society of Clinical Oncology Clinical Recommendations for the Use of White Blood Cell (WBC) Growth Factors states that, "Evidence suggests that pegfilgrastim administered 1-3 days after chemotherapy results in a lower risk of infection than pegfilgrastim administered on the same day as chemotherapy" [36]. The current version of the NCCN Guidelines ${ }^{\circledR}$ for Myeloid Growth Factors states that, "Beginning pegfilgrastim the day after chemotherapy is preferred" [21]. The favorable ANC trajectory and lower incidence proportion of CIN observed in the current study support these recommendations.

This study has several strengths. By performing a pooled analysis of clinical trial data from patients who 
were randomized to receive pegfilgrastim on the same day as chemotherapy or the next day, we avoided bias due to confounding, an issue that might affect other study designs. Our data included frequent measurements of ANC, which enabled good estimation of ANC trajectory and of the difference in AOC of ANC between the patients who received pegfilgrastim on the same day as chemotherapy versus the next day. Severity and duration of CIN were simultaneously captured by using AOC of ANC in this analysis, and potential covariates with imbalanced distributions were adjusted for when comparing AOC of ANC between the two treatment groups. Inclusion and exclusion criteria were applied in addition to the original criteria used in each trial (e.g., baseline ANC and body temperature and ANC measurement frequency within each chemotherapy cycle) to standardize patient selection in this analysis. Standardized definitions of study endpoints and covariates were also developed and applied in this study.

This study also has limitations. The original primary efficacy endpoint of the four clinical trials included in this analysis was duration of grade 4 neutropenia, and the trials were not designed to detect a difference in risk of infection/FN. The sample size in this pooled analysis was not sufficient to detect possible difference in the incidence proportions of FN between patients who received pegfilgrastim on the same day as chemotherapy versus the next day. Another limitation is that patients in the original studies did not have frequent enough measurements of ANC to allow examination of the ANC trajectory in all cycles of chemotherapy. In addition, patients enrolled in the original clinical trials might not be representative of patients with cancer treated in routine clinical practice today; thus, the results from this pooled analysis of clinical trial data might have limited generalizability.

\section{Conclusions}

In this secondary analysis of individual patient data from four randomized clinical trials, we found that patients who received pegfilgrastim as indicated, on the day after chemotherapy, had less severe and less sustained suppression of ANC as manifested by higher ANC nadirs and smaller AOC of ANC than patients who received pegfilgrastim on the same day as chemotherapy. Next-day patients also had lower incidence proportions of grade 3 or 4 CIN than sameday patients. No significant differences were observed in the incidence proportions of FN, likely due to the lack of statistical power in the study. Together, these results support administration of pegfilgrastim as indicated, on the day after chemotherapy.
Acknowledgments Micah Robinson, Ph.D., provided medical writing support on behalf of Amgen Inc.

Funding This study was funded by Amgen Inc.

\section{Compliance with ethical standards}

Conflict of interest Yanli Li, Zandra Klippel, Maureen Reiner, and John H. Page are employees of and own stock in Amgen Inc. Xiaolong Shih and Hong Wang are consultants to Amgen and are funded by Amgen Inc.

Ethical approval All procedures performed in studies involving human participants were in accordance with the ethical standards of the institutional and/or national research committee and with the 1964 Helsinki declaration and its later amendments or comparable ethical standards.

Informed consent Informed consent was obtained from all individual participants included in the original studies. For this type of study formal consent is not required.

Open Access This article is distributed under the terms of the Creative Commons Attribution 4.0 International License (http://creativecommons.org/licenses/by/4.0/), which permits unrestricted use, distribution, and reproduction in any medium, provided you give appropriate credit to the original author(s) and the source, provide a link to the Creative Commons license, and indicate if changes were made.

\section{References}

1. Amulic B, Cazalet C, Hayes GL, Metzler KD, Zychlinsky A (2012) Neutrophil function: from mechanisms to disease. Annu Rev Immunol 30:459-489. doi:10.1146/ annurev-immunol-020711-074942

2. Crawford J, Dale DC, Lyman GH (2004) Chemotherapy-induced neutropenia: risks, consequences, and new directions for its management. Cancer 100(2):228-237. doi:10.1002/cncr.11882

3. Crawford J, Kreisman H, Garewal H, Jones SE, Shoemaker D, Pupa MR, Armstrong S, Tomita D, Dziem G (1997) The impact of Filgrastim schedule variation on hematopoietic recovery postchemotherapy. Ann Oncol 8(11):1117-1124

4. Bodey GP, Buckley M, Sathe YS, Freireich EJ (1966) Quantitative relationships between circulating leukocytes and infection in patients with acute leukemia. Ann Intern Med 64(2):328-340

5. Rivera E, Haim Erder M, Fridman M, Frye D, Hortobagyi GN (2003) First-cycle absolute neutrophil count can be used to improve chemotherapy-dose delivery and reduce the risk of febrile neutropenia in patients receiving adjuvant therapy: a validation study. Breast Cancer Res 5(5):R114-R120. doi:10.1186/ bcr618

6. Silber JH, Fridman M, DiPaola RS, Erder MH, Pauly MV, Fox KR (1998) First-cycle blood counts and subsequent neutropenia, dose reduction, or delay in early-stage breast cancer therapy. J Clin Oncol 16(7):2392-2400

7. Kuderer NM, Dale DC, Crawford J, Cosler LE, Lyman GH (2006) Mortality, morbidity, and cost associated with febrile neutropenia in adult cancer patients. Cancer 106(10):2258-2266. doi: $10.1002 /$ cncr. 21847

8. Shayne M, Crawford J, Dale DC, Culakova E, Lyman GH, A. N. C. Study Group (2006) Predictors of reduced dose intensity in patients with early-stage breast cancer receiving 
adjuvant chemotherapy. Breast Cancer Res Treat 100(3):255262. doi:10.1007/s10549-006-9254-4

9. Weycker D, Edelsberg J, Kartashov A, Barron R, Lyman G (2012) Risk and healthcare costs of chemotherapy-induced neutropenic complications in women with metastatic breast cancer. Chemotherapy 58(1):8-18. doi:10.1159/000335604

10. Bhana N (2007) Granulocyte colony-stimulating factors in the management of chemotherapy-induced neutropenia: evidence based review. Curr Opin Oncol 19(4):328-335. doi:10.1097/01. cco.0000275309.58868.11

11. Lyman GH, Shayne M (2007) Granulocyte colony-stimulating factors: finding the right indication. Curr Opin Oncol 19(4):299307. doi:10.1097/CCO.0b013e3281a3c0ba

12. Crawford J, Ozer H, Stoller R, Johnson D, Lyman G, Tabbara I, Kris M, Grous J, Picozzi V, Rausch G, Smith R, Gradishar W, Yahanda A, Vincent M, Stewart M, Glaspy J (1991) Reduction by granulocyte colony-stimulating factor of fever and neutropenia induced by chemotherapy in patients with smallcell lung cancer. N Engl J Med 325(3):164-170. doi:10.1056/ NEJM199107183250305

13. Neulasta ${ }^{\circledR}$ (pegfilgrastim) prescribing information. Amgen

14. Chabner B, Longo DL (2011) Cancer chemotherapy and biotherapy: principles and practice, 5th edn. Wolters Kluwer Health/ Lippincott Williams \& Wilkins, Philadelphia

15. Meropol NJ, Miller LL, Korn EL, Braitman LE, MacDermott ML, Schuchter LM (1992) Severe myelosuppression resulting from concurrent administration of granulocyte colony-stimulating factor and cytotoxic chemotherapy. J Natl Cancer Inst 84(15):1201-1203. doi:10.1093/jnci/84.15.1201

16. Weycker D, Wu H, Hagiwara M, Li X, Barron RL (2014) Use of chemotherapy and same-day pegfilgrastim prophylaxis in US clinical practice. Blood 124(21):4825

17. Li S, Sosa IR, Molony JT, Page JH, Barron RL, Liu J, Morrow PK, Stryker S, Acquavella JF, Collins AJ (2014) Timing of primary prophylaxis G-CSF use during chemotherapy in elderly patients with NHL. Blood 124(21):6013

18. Weycker D, Li X, Figueredo J, Barron R, Tzivelekis S, Hagiwara $M$ (2015) Risk of chemotherapy-induced febrile neutropenia in cancer patients receiving pegfilgrastim prophylaxis: does timing of administration matter? Support Care Cancer. doi:10.1007/ s00520-015-3036-7

19. National Cancer Institute (2009) Common Terminology Criteria for Adverse Events (CTCAE) v4.0. National Cancer Institute. http://ctep.cancer.gov/protocolDevelopment/electronic_applications/ctc.htm

20. Mosteller RD (1987) Simplified calculation of bodysurface area. N Engl J Med 317(17):1098. doi:10.1056/ NEJM198710223171717

21. National Comprehensive Cancer Network. NCCN Clinical Practice Guidelines in Oncology (NCCN Guidelines ${ }^{\circledR}$ ). Myeloid Growth Factors. Version 1.2015. www.NCCN.org. Accessed 20 August 2015

22. Millward MJ, Boyer MJ, Lehnert M, Clarke S, Rischin D, Goh BC, Wong J, McNeil E, Bishop JF (2003) Docetaxel and carboplatin is an active regimen in advanced non-small-cell lung cancer: a phase II study in Caucasian and Asian patients. Ann Oncol 14(3):449-454. doi:10.1093/annonc/mdg 118

23. Lidstone GJ (1945) Note on logarithmic interpolation. Trans Fac Actuar 17:216-218. doi:10.1017/S0071368600002998

24. Petrovic JS (2014) Definite integral. In: Advanced calculus: theory and practice. CRC Press, Boca Raton, pp 135-168

25. Trillet-Lenoir V, Green J, Manegold C, Von Pawel J, Gatzemeier U, Lebeau B, Depierre A, Johnson P, Decoster G, Tomita D et al (1993) Recombinant granulocyte colony stimulating factor reduces the infectious complications of cytotoxic chemotherapy. Eur J Cancer 29A(3):319-324
26. Brugger W, Bacon P, Lawrinson S, Romieu G (2009) Neutrophil recovery in elderly breast cancer patients receiving adjuvant anthracycline-containing chemotherapy with pegfilgrastim support. Crit Rev Oncol Hematol 72(3):265-269. doi:10.1016/j. critrevonc.2009.05.002

27. Meza L, Baselga J, Holmes F, Liang B, Breddy J, for the Pegfilgrastim Study Group (2002) Incidence of febrile neutropenia (FN) is directly related to duration of severe neutropenia (DSN) after myelosuppressive chemotherapy. J Clin Oncol 21:255b (abstr 2840)

28. Li Y, Shih X, Klippel ZK, Reiner M, Page JH (2014) Relationship between severity and duration of chemotherapy induced neutropenia and risk of infection among patients with non-myeloid malignancies. Blood 124(21):4960

29. Burris HA, Belani CP, Kaufman PA, Gordon AN, Schwartzberg LS, Paroly WS, Shahin S, Dreiling L, Saven A (2010) Pegfilgrastim on the same day versus next day of chemotherapy in patients with breast cancer, non-small-cell lung cancer, ovarian cancer, and non-Hodgkin's lymphoma: results of four multicenter, double-blind, randomized phase II studies. J Oncol Pract 6(3):133-140. doi:10.1200/JOP.091094

30. Saven A, Schwartzberg L, Kaywin P, Bartlett N, Dean L, Shahin S, Dreiling L (2006) Randomized, double-blind, phase 2, study evaluating same-day vs next-day administration of pegfilgrastim with R-CHOP in non-Hodgkin's lymphoma patients. J Clin Oncol 24 (18_suppl; abstr 7570)

31. Belani CP, Ramalingam S, Al-Janadi A, Eskander E, Ghazal H, Schwartzberg L, Elliott M, Shahin S, Dreiling L (2006) A randomized double-blind phase II study to evaluate same-day vs nextday administration of pegfilgrastim with carboplatin and docetaxel in patients with NSCLC. J Clin Oncol 24 (18_suppl; abstr 7110)

32. Hoffmann PS (2005) Administration of pegfilgrastim on the same day or next day of chemotherapy. J Clin Oncol 23 (16_ suppl; abstr 8137)

33. Whitworth JM, Matthews KS, Shipman KA, Numnum TM, Kendrick JE, Kilgore LC, Straughn JM Jr (2009) The safety and efficacy of day 1 versus day 2 administration of pegfilgrastim in patients receiving myelosuppressive chemotherapy for gynecologic malignancies. Gynecol Oncol 112(3):601-604. doi:10.1016/j.ygyno.2008.10.025

34. Karol J, Rybicki L, Sweetenham J, Smith MR, Hill BT, Pohlman B, Jagadeesh D, Gazdick E, Fenner K, Maggiotto AL, Dean RM (2013) Similar incidence of febrile neutropenia with same-day versus subsequent day G-CSF administration in non-Hodgkin lymphoma patients receiving R-CHOP chemotherapy. Blood 122(21):4357

35. Cheng C, Gallagher EM, Yeh JY, Earl MA (2014) Rates of febrile neutropenia with pegfilgrastim on same day versus next day of CHOP with or without rituximab. Anticancer Drugs 25(8):964-969. doi:10.1097/CAD.0000000000000115

36. Smith TJ, Bohlke K, Lyman GH, Carson KR, Crawford J, Cross SJ, Goldberg JM, Khatcheressian JL, Leighl NB, Perkins CL, Somlo G, Wade JL, Wozniak AJ, Armitage JO (2015) Recommendations for the use of WBC growth factors: American Society of Clinical Oncology clinical practice guideline update. J Clin Oncol 33(28):3199-3212. doi:10.1200/JCO.2015.62.3488

37. Kaufman PA, Paroly W, Rinaldi D, Sonnier S, Shahin S, Dean L, Dansey R, Burris S (2004) Randomized, double-blind, phase 2 study evaluating same-day vs next-day administration of pegfilgrastim with docetaxel, doxorubicin, and cyclophosphamide (TAC) in women with early stage and advanced breast cancer. Breast Cancer Res Treat 88(1 suppl):S59 (abstr 1054) 